\title{
Deteksi Kelayuan Pada Bunga Mawar dengan Metode Transformasi Ruang Warna Hue Saturation Intensity (HSI) dan Hue Saturation Value (HSV)
}

\author{
Dede Wandi', Fauziah, Nur Hayati \\ Fakultas Teknologi Komunikasi dan Informatika, Informatika, Universitas Nasional, Jakarta, Indonesia \\ Email: 1,*dedewandi5@gmail.com, ${ }^{2}$ fauziah@civitas.unas.ac.id, ${ }^{3}$ nurhayati@civitas.unas.ac.id \\ Email Penulis Korespondensi: dedewandi5@gmail.com
}

\begin{abstract}
Abstrak-Bunga mawar salah satu tanaman dari genus Rosa. Bunga mawar terdiri dari 100 spesies lebih dengan berbagai warna. Dalam memilih dan memilah bunga mawar sering ditemukan bunga mawar yang masih segar dan layu. Berdasarkan permasalahan yang dihadapi pada bunga mawar, dilakukanlah sebuah perancangan sistem yang dapat mendeteksi tentang kondisi kelayuan pada bunga mawar. Dengan menerapkan metode HSI dan HSV pada aplikasi pengolahan citra, diharapkan dapat membantu dalam memilih kondisi bunga mawar. Dengan metode penelitian melalui observasi dan studi literatur. Untuk melihat kondisinya bunga mawar dapat dibedakan menjadi bunga layu dan bunga segar. Dalam implementasi dan klasifikasinya dengan mendeteksi warna pada bunga mawar dalam ruang warna HSI dan HSV dari total 230 gambar citra bunga mawar merah dan putih yang diuji 200 gambar dengan menggunakan HSI dan HSV didapat nilai Range pada HSI, $\mathrm{H}=0.240634-0.5, \mathrm{~S}=$ $0.781818-1$, dan I $=0.477124-1$ dengan kategori Segar, sedangkan Kategori Layu HSI, H $=0.170495-0.5, \mathrm{~S}=0.40239-1$ , $\mathrm{I}=0.562092-1$. dan didapat pula nilai Range dengan HSV dengan kategori Segar $\mathrm{H}=0.240634-0,5, \mathrm{~S}=0-0.988235, \mathrm{~V}$ $=0-0.988235$, dan kategori Layu $\mathrm{H}=0.170495-0.5, \mathrm{~S}=0-0.996078, \mathrm{~V}=0-0.996078$. Dengan nilai akurasi pada HSI dan HSV sebesar 86,9 \%. Maka dari itu dapat disimpulkan bahwa deteksi kelayuan pada bunga mawar dengan metode HSI dan HSV yang paling cepat dalam prosesnya adalah menggunakan metode HSI dikarenakan terbacanya seluruh nilai min-max.
\end{abstract}

Kata Kunci: Deteksi Kelayuan; Deteksi Bunga Mawar; Pengolahn Citra; HIS; HSV

\begin{abstract}
The rose is a plant of the genus Rosa. The rose consists of more than 100 species with various colors. In selecting and sorting roses, roses are often found that are still fresh and wilted. Based on the problems faced in roses, a system design is carried out that can detect the wilting condition of roses. By applying the HSI and HSV methods to image processing applications, it is hoped that it can help in choosing the condition of roses. With research methods through observation and literature study. To see the conditions, roses can be divided into wilted flowers and fresh flowers. In its implementation and classification, by detecting the color of roses in the HSI and HSV color space, from a total of 230 images of red and white roses that tested 200 images using HSI and HSV, the value of Range was obtained on the HSI, $\mathrm{H}=0.240634-0.5, \mathrm{~S}=0.781818-$ 1 , and $\mathrm{I}=0.477124-1$ in the Fresh category, while the HSI Wilt Category, $\mathrm{H}=0.170495-0.5, \mathrm{~S}=0.40239-1, \mathrm{I}=0.562092$ - 1. and also obtained the value of Range with HSV with Fresh category $\mathrm{H}=0.240634-0.5, \mathrm{~S}=0-0.988235, \mathrm{~V}=0-0.988235$, and Wilt category $\mathrm{H}=0.170495-0.5, \mathrm{~S}=0-0.996078, \mathrm{~V}=0-0.996078$. With an accuracy value of the HSI and HSV of $86.9 \%$. Therefore, it can be concluded that the detection of wilting in roses using the HSI and HSV methods is the fastest in the process using the HSI method because it reads all the min-max values.
\end{abstract}

Keywords: Withering Detection; Rose Detection; Image Processing; HIS; HSV

\section{PENDAHULUAN}

Salah satu kekayaan flora yang ada di Indonesia adalah bunga mawar dari genus Rosa yang terdiri dari 100 spesies lebih dengan berbagai warna. Pada proses pemilihan bunga mawar biasanya ditemukan bunga yang segar dan layu. Kelayuan pada bunga bisa dilihat dari tekstur warna pada bunga tersebut, setiap bunga mawar memiliki warna kelayuan yang berbeda dengan itu harus dilakukan segmentasi warna pada bunga yang merupakan pemisahan segmen dalam suatu citra berdasarkan warna yang terkandung dalam citra [1]. Segmentasi citra merupakan bagian dari proses pengolahan citra[2]. Citra yang kaya dengan informasi memiliki karakterisitik yang tidak dimiliki oleh data teks [3].

Perlu dilakukan untuk pemilihan kelayuan pada bunga dengan tujuan dari penelitian ini adalah menemukan parameter terkait warna kelayuan dengan proses ekstraksi fitur dalam segmentasi ruang warna HSI dan HSV. Harapannya bahwa parameter ini dapat dijadikan sebagai set poin untuk melakukan proses deteksi kelayuan yang dapat dikombinasikan dengan metode pengolahan citra lainnya dengan objek tetap warna kelayuan pada bunga mawar dengan model warna RGB adalah model warna yang berdasarkan konsep penambahan kuat cahaya primer yaitu red, green, dan blue[4].

Pada penelitian sebelumnya oleh Fitri dan Abdul dengan "Sistem Pengenalan Bunga Berbasis Pengolahan Citra dan Pengklasifikasi Jarak" memperoleh tingkat akurasi tertinggi 85\% dengan metode jarak manhattan dengan ektraksi ciri histogram dan paling rendah tingkat akurasinya sebesar $77 \%$, menggunakan metode klasifikasi Euclidean [5]. Penelitian tentang deteksi menggunakan transformasi warna HSI telah dilakukan oleh Edha dengan judul "Penerapan Metode Transformasi Ruang Warna Hue Saturation Intensity (HSI) Untuk Mendeteksi Kematangan Buah Mangga Harum Manis" [6]. Hasil penelitiannya mendapatkan hasil presentasi yang baik yaitu 87\% pada tingkat keberhasilannya. Dan penelitian tentang deteksi menggunakan transformasi warna HSV oleh Nina dengan judul "Identifikasi Tingkat Kematangan Buah Pisang Menggunakan Metode Ektraksi Ciri Statistik Pada Warna Kulit Buah" [7]. Dengan tingkat presentasi keberhasilan sebesar 90\%. 
Pada Penelitian Rianto dan Harjoko "Penentuan Kematangan Buah Salak Pondoh Di Pohon Berbasis Pengolahan Citra Digital" yang menggunakan metode segmentasi warna RGB dan gray, serta kNearest Neighbor dengan mengetahui nilai mean $\mathrm{R}$ dan mean $\mathrm{V}$ yang dimana setiap piksel buah salak pondoh dihitung besar ketidak miripannya terhadap nilai data fitur RGB dan gray pembanding kemudian di klasifikasi [8]. Dan penelitian Lestary pada "Deteksi Penyakit Tanaman Jeruk Siam Berdasarkan Citra Daun Menggunakan Segmentasi Warna RGBHSV" dengan pengklasifikasikan jenis penyakit pada daun jeruk menggunakan Fuzzy K-Nearest Neighbor [9].

Untuk proses pemilihan bunga dapat menerapkan metode Hue Saturation Intensity (HSI) dan Hue Saturation Value (HSV) pada aplikasi pengolahan citra. Model HSI memiliki kemampuan untuk memisahkan intensitas informasi intrinsik warna, yang mengacu pada Hue dan Saturation, sedangkan proses HSV didasarkan pada ciri warna bunga mawar dengan mengambil nilai RGB (Red, Green, dan Blue) pada citra. Model ini cocok untuk mengolah citra yang menghadirkan perubahan pencahayaan, karena disebabkan warna lingkungan dapat dibedakan satu sama lain melalui komponen Hue [10] yang bertujuan untuk menentukan kelayuan pada bunga mawar tersebut, dengan membatasi permasalahnya hanya mendeteksi kelayuan pada bunga mawar dengan metode HSI dan HSV, dengan menggunakan K-NN untuk klasifikasi data baru berdasarkan jarak terdekat ke sejumlah data latih [11].

Pembuatan sistem pengolah citra untuk mendeteksi kelayuan dibuat dengan pengolahan citra pada matlab, bermaca-macam pengolahan gambar warna salah satunya model rgb atau normalisasi RGB. Model pengolahan citra ini merupakan pengolahan warna dengan menghitung prosentase warna RGB dalam sebuah citra [12]. Proses segmentasi merupakan proses pemisah bagian dalam citra untuk mendapatkan hasil pengenalan objek yang akurat [13]. model yang dibentuk model RGB merupakan hasil campuran dari warna primer [14].

\section{METODOLOGI PENELITIAN}

\subsection{Desain Penelitian}

Pada penelitian ini menggunakan metodelogi agile yang merupakan pengembangan perangkat lunak yang pengembangan sistemnya jangka pendek yang memerlukan penyesuaian cepat pada sebuah pengembangan terhadap suatu perubahan apapun yang berdasarkan pada prinsip-prinsip yang sama. Tim yang tanggap terhadap suatu perubahan yang mempunyai salah satu ciri dari Angile Software Development[15].

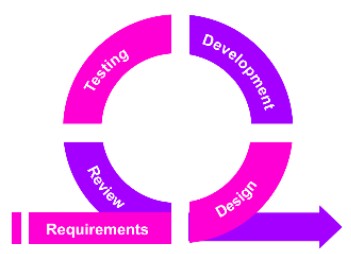

Gambar 1. Metodelogi Agile

Pendekatan agile pada penelitian ini terdiri dari :

1. Requirements, yaitu menentukan peralatan apa saja yang dibutuhkan dan spesifikasi yang diperlukan selama penelitian.

2. Design, Membuat dan merancang sebuah desain yang berdasarkan kebutuhan spesifikasi yang telah ditentukan sebelumnya pada tahapan pertama.

3. Development, pada tahapan ini mengimplementasikan sebuah program yang dibutuhkan sesuai yang dibuat pada tahapan design.

4. Testing, pada tahapan testing ini pengujian sistem dilakukan yang berguna untuk menguji kesesuaian sistem yang telah di develop sebelumnya agar hasil yang diharapkan bisa sesaui.

5. Review, tahapan ini merupakan evaluasi sistem dan memelihara sistem yang telah dibuat berdasarkan tahapan sebelumnya yang bertujuan agar tidak mengurangi performa dari sistem yang telah dirancang.

Desain penelitian dengan menggunakan pendekatan agile lebih efisien dan efektif dikarenakan setiap kesalahan atau kekurangan pada setiap tahapan bisa langsung dilakukan perbaikan, sehingga hasil yang didapat lebih maksimal. Dimana metodologi ini dalam pengembangan sistemnya jangka pendek yang membutuhkan adaptasi cepat dari sisi pengembang terhadap perubahan yang ada di lapangan [16].

\subsection{Pengumpulan Data}

Dalam penelitian ini untuk mendaptkan data yang dibutuhkan, yaitu dengan melalui observasi dan studi literatur untuk diambil beberapa citra untuk dijadikan data yang diuji. Cara observasi ini dilakukan yaitu dengan pengumpulan sebuah data maupun fakta yang secara langsung dilakukan pengamatan terhadap objek yang akan diteliti yang nantinya data tersebut sesuai yang dibutuhkan dengan hasil yang diinginkan. 


\section{JURNAL MEDIA INFORMATIKA BUDIDARMA}

Volume 5, Nomor 1, Januari 2021, Page 308-316

ISSN 2614-5278 (media cetak), ISSN 2548-8368 (media online)

Available Online at https://ejurnal.stmik-budidarma.ac.id/index.php/mib DOI 10.30865/mib.v5i1.2562

Pada studi literatur yang telah diperoleh dari literatur yang dilakukan yang berhubungan dengan tema yang sesuai seperti pengolahan citra dan deteksi warna pada berbagai objek, berdasarkan pada warna. Dengan dilakukannya motode tersebut bertujuan agar bisa mendukung dasar teori dengan mengacu pada penelitian yang didilakukan sebelumnya.

\subsection{Analisis Data}

Pada proses analisi data ini yang dilakukan yaitu menghitung data penelitian yang sudah di ekstraksi kedalam Excel untuk di analisis. Dari keseluruhan data yang diinputkan kedalam Excel, dibuatkan pivot untuk dihitung hasil keseluruhan dari data yang diujikan.
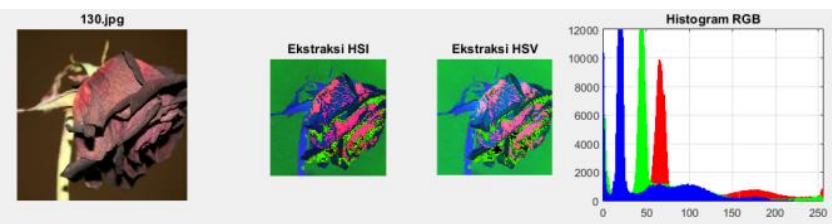

Gambar 2. Konsep Dasar deteksi Kelayuan Bunga Mawar

\subsection{Transformasi Ruang Warna HSI ( Hue Saturation Intensity) dan HSV (Hue Saturation Value)}

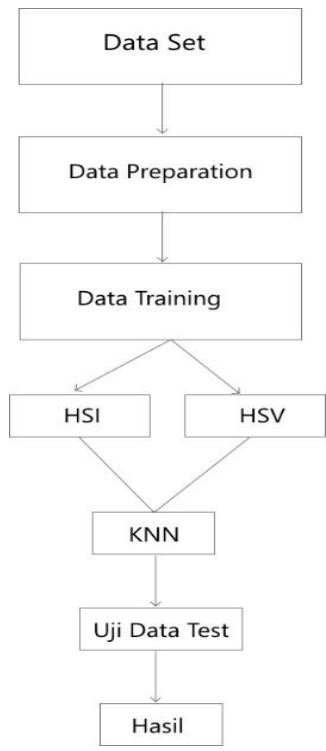

Gambar 3. Tahapan Penelitian Pada Deteksi Kelayuan

Tahapan diatas menjelaskan alur dari proses kompresi citra pertama dilakukan pengumpulan data set yang akan diuji pada sistem, dalam pengumpulan data set ini dibuat dengan data gambar bunga layu dan segar. Dalam prosesnya dilakukan preparasi data gambar untuk mendapatkan data gambar bunga mawar yang segar dan layu. Pengelompokan yang dijadikan sebagai data uji dan data latih untuk mendapatkan nilai HSI dan HSV.

Selanjutnya training data gambar uji bunga mawar dengan metode HSI dan HSV, Pada HSI yaitu dilakukan training data dari RGB ke HSI. Warna dasar pada RGB merupakan warna yang dijadikan patokan yang warnanya akan tampil secara universal yang warnanya bisa diubah kedalam kode-kode [17]. Dengan rumus menghitung nilai rgb dalam bentuk normalisasi:

$$
\mathrm{R}=\frac{R}{(\mathrm{R}+\mathrm{G}+\mathrm{B})} \mathrm{g}=\frac{\mathrm{G}}{(\mathrm{R}+\mathrm{G}+\mathrm{B})} \mathrm{b}=\frac{B}{(\mathrm{R}+\mathrm{G}+\mathrm{B})}
$$

Pada rumus diatas dibuat kedalam program matlab untuk mengahasilkan nilai dari RGB tersebut. Pada Rumus Hue dihitung dengan menggunakan rumus.

$$
\begin{aligned}
& \theta=\cos -1\left\{\frac{\frac{1}{2}[(\mathrm{R}-\mathrm{G})+(\mathrm{R}-\mathrm{B})]}{\left[(\mathrm{R}-\mathrm{G})^{2}+(\mathrm{R}-\mathrm{B})(\mathrm{G}-\mathrm{B})\right] \frac{1}{2}}\right\} \\
& \mathrm{H}=\left\{\begin{array}{cc}
\theta & \text { Jika } B \leq G \\
360 \theta & \text { Jika } B>G
\end{array}\right.
\end{aligned}
$$

Pada komponen saturation dihitung dengan menggunakan rumus :

$$
\mathrm{S}=1-\frac{3}{\min (\mathrm{R}, \mathrm{G}, \mathrm{B})} \min (R, G, B)
$$

Menghitung nilai intensity

$$
I=\frac{1}{2}(R+G+B)
$$


JURNAL MEDIA INFORMATIKA BUDIDARMA

Volume 5, Nomor 1, Januari 2021, Page 308-316

ISSN 2614-5278 (media cetak), ISSN 2548-8368 (media online)

Available Online at https://ejurnal.stmik-budidarma.ac.id/index.php/mib

DOI 10.30865/mib.v5i1.2562

Dengan rumus 1-4, dibuat kedalam sebuah program matlab untuk dicari nilai HSI yang dihasilkan.

Pada perhitungan HSV dilakukan dengan menganalisis nilai warna tiap piksel citra sesuai fitur yang diinginkan dengan nilai toleransi pada setiap dimensi warna HSV [18]. Untuk menghitung nomalisai RGB sama seperti pada rumus 1. Untuk menghitung nilai Hue pada HSV

$$
\begin{aligned}
& \theta=\cos -1\left\{\frac{\frac{1}{2}[(\mathrm{R}-\mathrm{G})+(\mathrm{R}-\mathrm{B})]}{\left[(\mathrm{R}-\mathrm{G})^{2}+(\mathrm{R}-\mathrm{B})(\mathrm{G}-\mathrm{B})\right] \frac{1}{2}}\right\} \\
& \mathrm{H}=\left\{\begin{array}{cc}
\theta & \text { Jika } B \leq G \\
360 \theta & \text { Jika } B>G
\end{array}\right.
\end{aligned}
$$

Menghitung nilai Value:

$$
V=\max (r, g, b)
$$

Menghitung nilai Saturasi:

$$
\mathrm{S}=\left\{\begin{array}{lr}
\theta & \text { Jika } V=0 \\
1-\frac{\min (\mathrm{r}, \mathrm{g}, \mathrm{b})}{\mathrm{v}} & \text { Jika } V>0
\end{array}\right.
$$

Untuk mencari nilai HSV dari rumus 5-7, sama dibuat kedalam sebuah program matlab untuk dicari nilai HSV yang dihasilkan.

Selanjutnya menentukan klasifikasi setiap hasil yang diperoleh dengan metode K-Nearest Neighbor $(\mathrm{KNN})$, metode ini melakukan klasifikasi terhadap objek nilai warna yang telah dihasilkan berdasarkan data pembelajaran yang telah di ektraksi. KNN menggunakan data pembelajaran dengan jarak yang akan dievaluasi dengan $\mathrm{k}=\mathrm{n}$ [19]. Yang nantinya untuk diklasifikasikan pada objek baru yang berdasarkan atribut dan data training sample yang akan diuji.

Sebelum dilakukan perhitungan, terlebih dahulu harus menentukan data latih dan data uji. KNN merupakan metode yang digunakan untuk pencarian, klasifikasi, klustering [20].

$$
d i=\sqrt{\sum_{1}^{n}=i^{(x 1 i-x 2 i)^{2}}}
$$

Rumus KNN ini dibuat kedalam program matlab untuk mencari kalisifikasi pada bunga mawar tersebut. Apakah bunga mawar termasuk layu atau segar.

Untuk mengetahui seberapa akurasi data yang sudah ditraining dengan metode HSI dan HSV dilakukan pengujian pada sistem agar output yang dihasilkan bisa sesuai dengan algoritmanya. Data uji test ini dilakukan secara manual dengan 100 data gambar bunga layu dan 100 data gambar bunga segar yang kemudian hasil outputnya akan terbaca salah ataupun benar. Pada perhitungan uji akurasi pada sistem Menggunakan rumus sebagai berikut:

$$
\text { Akurasi }=\frac{\text { Jumlah Nilai Kebenaran }}{\text { Jumlah Sampel }} \times 100 \%
$$

\section{HASIL DAN PEMBAHASAN}

Penelitian ini dirancang dengan menggunakan software MATLAB 2017b dengan tampilan GUI. Tampilan yang dibangun pada aplikasi deteksi kelayuan bunga mawar.

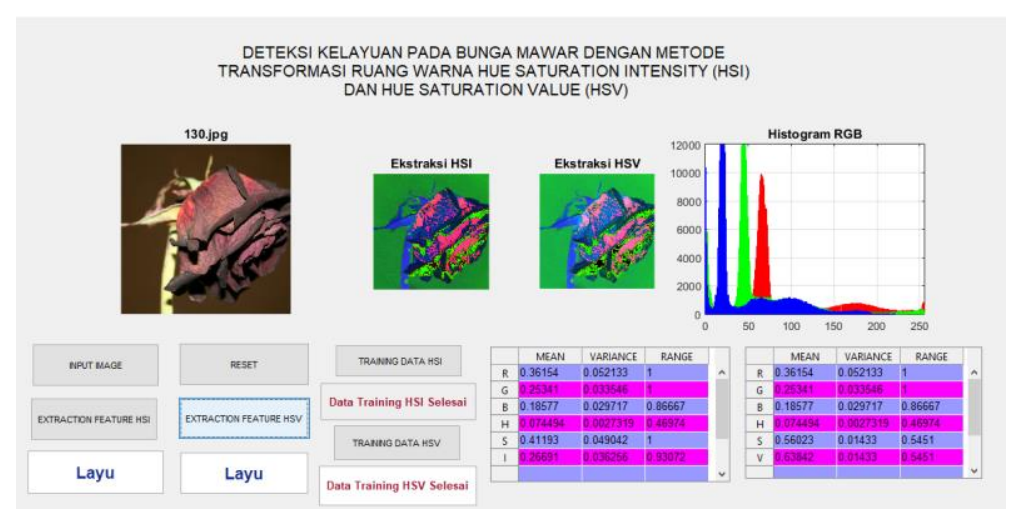

Gambar 4. Tampilan Aplikasi Deteksi Kelayuan Bunga Mawar 
JURNAL MEDIA INFORMATIKA BUDIDARMA

Volume 5, Nomor 1, Januari 2021, Page 308-316

ISSN 2614-5278 (media cetak), ISSN 2548-8368 (media online)

Available Online at https://ejurnal.stmik-budidarma.ac.id/index.php/mib DOI 10.30865/mib.v5i1.2562

Adapun fitur yang ditampilkan dalam aplikasi yang dirancang diantaranya:

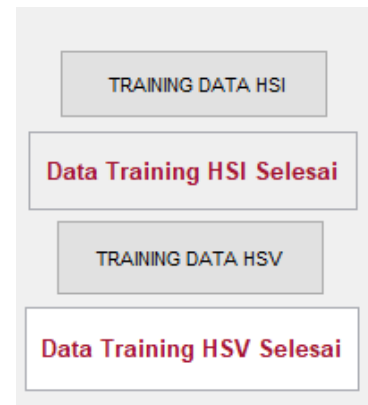

Gambar 5. Data Training HSI dan HSV

Pada gambar 5 data semua gambar uji akan di training dengan menggunakan algoritma HSI dan algoritma HSV, yang dimana jika data telah selesai di training akan masuk kedalam excel dengan keseluruhan nilai pada masing-masing gambar.

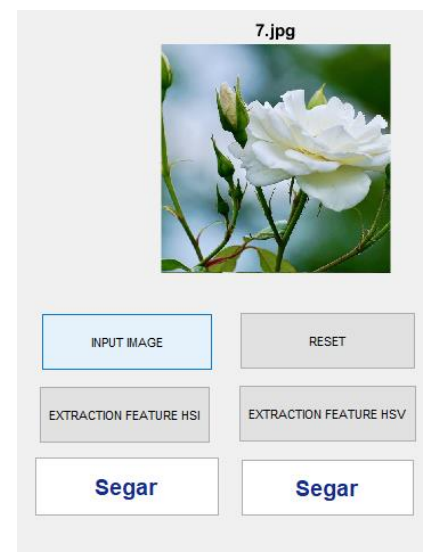

Gambar 6. Ekstraksi Bunga Untuk Mengetahui Jenis Kelayuan

Pada gambar 6, Input bunga mawar untuk di ektraksi apakah bunga mawar tersebut termasuk ke jenis bunga segar atau layu.

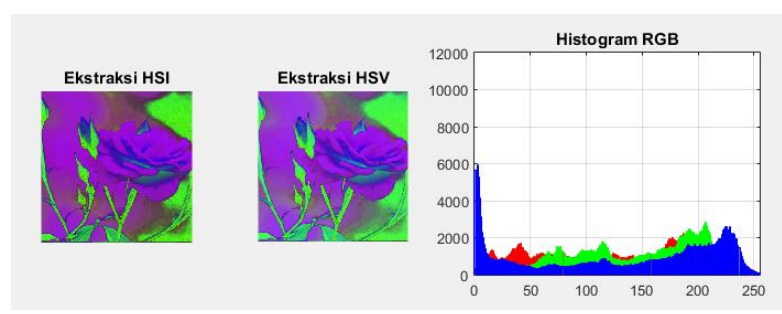

Gambar 7. Ektraksi HSI dan HSV

Pada gambar 7, hasil ektraksi bunga mawar dengan HSI dan HSV dan ditunjukan dengan Hologram RGB dmna besaran nilai RGB pada warna bunga.
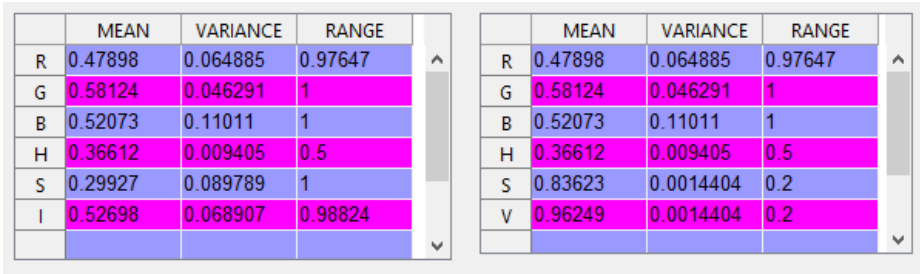

Gambar 8. Hasil Nilai Masing-Masing HSI dan HSV

Pada gambar 8, memberikan informasi detail nilai RGB HSI dan RGB HSV yang telah ditraining pada semua gambar uji. 


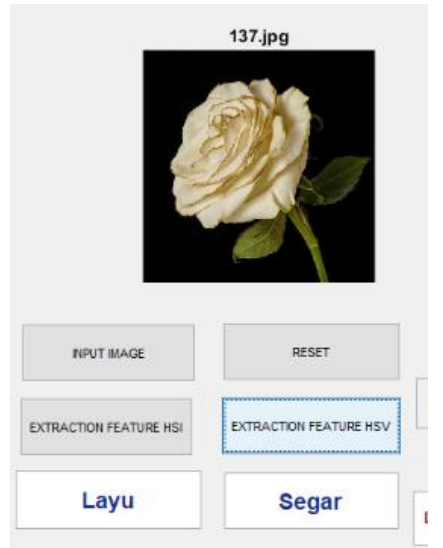

\section{Gambar 9. Hasil Data Uji Test Pada Sistem}

Pada gambar 9, memberikan informasi yang dilakukan pada data uji test bunga mawar segar maupun layu yang hasil pengujiannya akan membaca kebenaran atau kesalahan pada hasil pengujian sistem. Pengujian dilakukan pada 200 data gambar bunga mawar putih dan merah dengan jumlah keseluruhan data 230 gambar yang didapat dari sumber internet. Yang dimana data uji 100 data gambar bunga layu dan 100 data gambar bunga yang masih segar, yang kemudian dilakukan pengujian terhadap semua data gambar dengan kedua algoritma HSI dan HSV berdasarkan pada ciri warna.

Berkut hasil nilai yang telah dilakukan untuk klasifikasi pendeteksian kelayuan pada semua data bunga dengan menggunakan HSI dan HSV.

Tabel 1. Kelayuan Pada HSI min-max

\begin{tabular}{llll}
\hline & RANGE HSI & & Kategori \\
\hline $\mathbf{H}$ & 0.240634 & 0.5 & Segar \\
$\mathbf{S}$ & 0.781818 & 1 & \\
$\mathbf{I}$ & 0.477124 & 1 & \\
$\mathbf{H}$ & 0.170495 & 0.5 & Layu \\
$\mathbf{S}$ & 0.40239 & 1 & \\
$\mathbf{I}$ & 0.562092 & 1 & \\
\hline
\end{tabular}

Pada tabel 1 menampilkan nilai range HSI dari 100 data segar dan 100 data layu yang didapatkan dari hasil pengujian, dengan kategori nilai segar dan layu yang terdapat pada tabel.

Tabel 2. Kelayuan Pada HSV min-max

\begin{tabular}{llll}
\hline & \multicolumn{2}{l}{ RANGE HSV } & Kategori \\
\hline H & 0.240634 & 0.5 & Segar \\
S & 0 & 0.988235 & \\
V & 0 & 0.988235 & \\
H & 0.170495 & 0.5 & Layu \\
S & 0 & 0.996078 & \\
V & 0 & 0.996078 & \\
\hline
\end{tabular}

Pada tabel 2 menampilkan nilai range HSV dari 100 data segar dan 100 data layu yang didapatkan dari hasil pengujian, dengan kategori nilai segar dan layu yang terdapat pada tabel.

Untuk mendapatkan klasifikasi kelayuan pada bunga dilakukan klasifikasi dengan KNN yang dibuat dengan dua data jenis klasifikasi, yang ke 1 segar dan ke 2 Layu. Dengan jumlah nilai rata - rata keseluruhan data uji HSI dan HSV.

Sebelum menentukan jarak eucledian dari masing masing data digunakan centroid untuk mencari nilai tersebut.

Tabel 3. Nilai Rata-rata Range HSI

\begin{tabular}{ccc}
\hline \multicolumn{3}{c}{ Nilai Rata Rata Range } \\
\hline $\mathbf{H}$ & $\mathrm{S}$ & $\mathrm{I}$ \\
0.195972 & 0.390835 & 0.417953 \\
0.13893 & 0.232445 & 0.469809 \\
\multicolumn{3}{c}{ Nilai Rata Rata HSI } \\
\hline 0.10792 & 0.242485 & 0.220325 \\
0.0939 & 0.191406 & 0.22552 \\
\hline
\end{tabular}


JURNAL MEDIA INFORMATIKA BUDIDARMA

Volume 5, Nomor 1, Januari 2021, Page 308-316

ISSN 2614-5278 (media cetak), ISSN 2548-8368 (media online)

Available Online at https://ejurnal.stmik-budidarma.ac.id/index.php/mib

DOI 10.30865/mib.v5i1.2562

Tabel 4. Nilai Rata-rata Range HSV

\begin{tabular}{ccc}
\hline \multicolumn{3}{c}{ Nilai Rata Rata Range } \\
\hline $\mathbf{H}$ & $\mathbf{S}$ & $\mathbf{V}$ \\
0.195972 & 0.663707 & 0.768684 \\
0.13893 & 0.620682 & 0.776679 \\
\multicolumn{3}{c}{ Nilai Rata Rata HSV } \\
\hline 0.1079204 & 0.130006 & 0.130006 \\
0.0938996 & 0.092692 & 0.092692 \\
\hline
\end{tabular}

Langkah berikutnya adalah menggunakan perhitungan dari sebelumnya untuk menentukan apakah data uji yang dimasukan termasuk kedalam kategori segar atau layu. Untuk metode KNN adalah dengan menentukan nilai $\mathrm{k}$ terlebih dahulu. Kemudian untuk menentukan klasifikasi berdasarkan dari data latih yang akan dibandingkan dengan data uji. Kemudian akan dicari jarak terdekat dan akan diklasifikasi menurut jarak terdekat tetangga.

KNN HSI

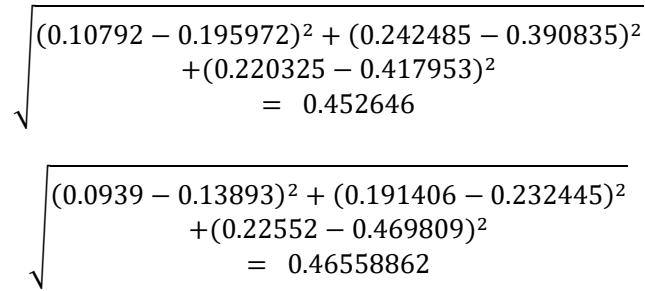

\section{KNN HSV}

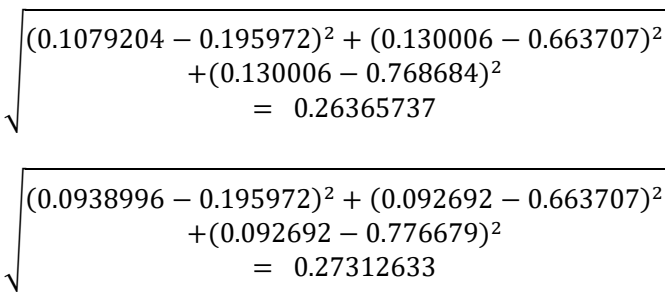

Tabel 5. Klasifikasi HSI

\begin{tabular}{ccc}
\hline Urutan Jarak & Nilai Jarak & Kelas \\
\hline $\mathbf{1}$ & 0.452646 & Segar \\
$\mathbf{2}$ & 0.46558862 & Layu \\
\hline
\end{tabular}

Tabel 6. Klasifikasi HSV

\begin{tabular}{ccc}
\hline Urutan Jarak & Nilai Jarak & Kelas \\
\hline $\mathbf{1}$ & 0.26365737 & Segar \\
$\mathbf{2}$ & 0.27312633 & Layu \\
\hline
\end{tabular}

Rumus perhitungan uji akurasi pada sistem terdapat pada rumus 9.

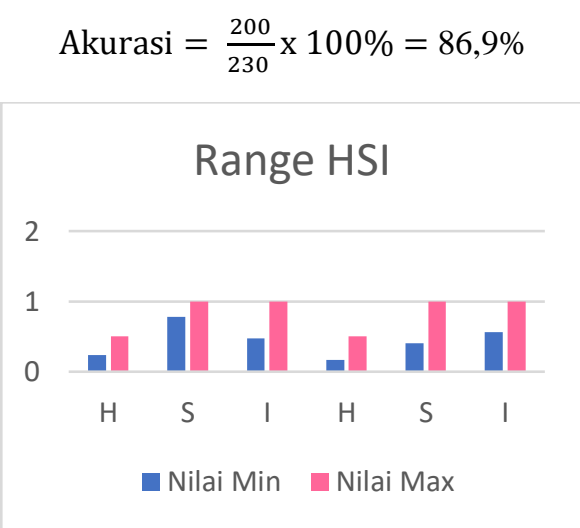

Gambar 10. Diagram Range HSI dengan Pivot 


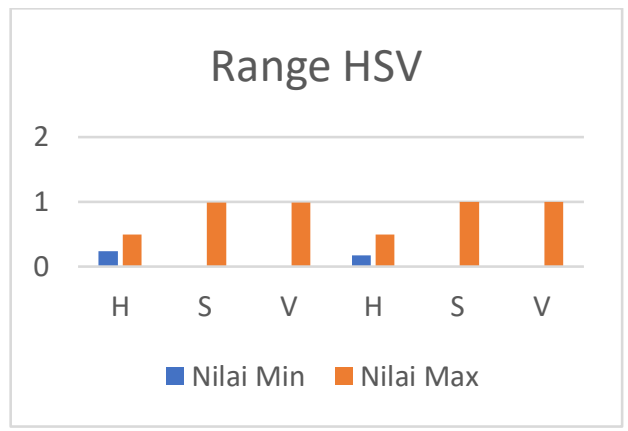

Gambar 11. Diagram Range HSV dengan Pivot

Pada diagram gambar 10 dan 11, menunjukan bahwa HSI dan HSV untuk mengekstraksi kelayuan bunga mawar berdasarkan pada warna. Pada diagram gambar 10 yaitu HSI memberikan nilai yang lebih baik diantara nilai min-max, sedangkan pada HSV gambar 11 nilai min dan max tidak begitu terbaca atau tidak ada nilai (0).

\section{KESIMPULAN}

Berdasarkan pembahasan diatas, maka dapat disimpulkan dari total 230 gambar citra bunga mawar merah dan putih yang diuji 200 gambar dengan menggunakan HSI dan HSV didapat nilai Range pada HSI, $\mathrm{H}=0.240634-$ $0.5, \mathrm{~S}=0.781818-1$, dan I =0.477124 -1 dengan kategori Segar, sedangkan Kategori Layu HSI, H =0.170495 $-0.5, \mathrm{~S}=0.40239-1, \mathrm{I}=0.562092-1$. dan didapat pula nilai Range dengan HSV dengan kategori Segar $\mathrm{H}=$ $0.240634-0,5, \mathrm{~S}=0-0.988235, \mathrm{~V}=0-0.988235$, dan kategori Layu $\mathrm{H}=0.170495-0.5, \mathrm{~S}=0-0.996078, \mathrm{~V}$ $=0$ - 0.996078. Dengan nilai akurasi pada HSI dan HSV sebesar 86,9\%. Maka dari itu dapat disimpulkan bahwa deteksi kelayuan pada bunga mawar dengan metode transformasi ruang warna HSI (Hues Saturation Intensity) dan HSV (Hue Saturation Value) yang paling cepat dalam prosesnya adalah menggunakan metode HSI dikarenakan terbacanya nilai min-max pada range HSI.

\section{REFERENCES}

[1] B. Yoga et al., "Segmentasi warna citra dengan deteksi warna hsv untuk mendeteksi objek," J. Inform., vol. 6, no. 2, 2010.

[2] A. N. H, M. Ichwan, and I. M. S. Putra, "Segmentasi Citra Untuk Deteksi Objek Warna Pada Aplikasi Pengambilan Bentuk Citra Rectangle,” J. Unpubl., pp. 1-10, 2015.

[3] Y. Permadi and Murinto, "Aplikasi Pengolahan Citra Untuk Identifikasi Kematangan Mentimun Berdasarkan Tekstur Kulit Buah Menggunakan Metode Ekstraksi Ciri Statistik,” J. Inform., vol. 9, no. 1, pp. 1028-1038, 2015.

[4] D. A. Prabowo, D. Abdullah, and A. Manik, "DETEKSI DAN PERHITUNGAN OBJEK BERDASARKAN WARNA MENGGUNAKAN COLOR OBJECT TRACKING,” vol. V, no. September, pp. 85-91, 2018.

[5] F. Muwardi and A. Fadlil, "Sistem Pengenalan Bunga Berbasis Pengolahan Citra dan Pengklasifikasi Jarak," J. Ilm. Tek. Elektro Komput. dan Inform., vol. 3, no. 2, p. 124, 2018, doi: 10.26555/jiteki.v3i2.7470.

[6] H. Edha, S. H. Sitorus, U. Ristian, J. Rakayasa, and S. Komputer, "Penerapan Metode Transformasi Ruang Warna Hue Saturation Intensity (HSI) Untuk Mendeteksi Kematangan Buah Mangga Harum Manis,” J. Komput. dan Apl., vol. 08, no. 1, pp. 1-10, 2020.

[7] N. Sularida, J. Y. Sari, I. Purwanti, and N. Purnama, "Identifikasi Tingkat Kematangan Buah Pisang Menggunakan Metode Ektraksi Ciri Statistik Pada Warna Kulit Buah," ULTIMATICS, vol. X, no. 2, 2018, doi: 10.31937/ti.v10i2.1004.

[8] P. Rianto and A. Harjoko, "Penentuan Kematangan Buah Salak Pondoh Di Pohon Berbasis Pengolahan Citra Digital," IJCCS (Indonesian J. Comput. Cybern. Syst., vol. 11, no. 2, p. 143, 2017, doi: 10.22146/ijccs.17416.

[9] F. R. Lestari, J. Y. Sari, Sutardi, and I. Purwanti, "Deteksi Penyakit Tanaman Jeruk Siam Berdasarkan Citra Daun Menggunakan Segmentasi Warna RGB-HSV," no. December, pp. 276-283, 2018.

[10] E. Blotta, A. Bouchet, V. Ballarin, and J. Pastore, "Enhancement of medical images in HSI color space," J. Phys. Conf. Ser., vol. 332, no. 1, 2011, doi: 10.1088/1742-6596/332/1/012041.

[11] A. Qur'ania, L. Karlitasar, and S. Maryana, "Analisis Tektur Dan Ekstraksi Fitur Warna Untuk Klasifikasi Apel Berbasis Citra," pp. 296-304, 2012.

[12] A. N. T. RD. Kusumanto, "Pengolahan Citra Digital Untuk Mendeteksi Obyek Menggunakan Pengolahan Warna Model Normalisasi Rgb," Semin. Nas. Teknol. Inf. Komun. Terap. 2011, 2011, doi: 10.1016/S0166-1116(08)71924-1.

[13] A. K. Panggabean, A. Syahfaridzah, and N. A. Ardiningih, "Mendeteksi Objek Berdasarkan Warna Dengan Segmentasi Warna HSV Menggunakan Aplikasi Matlab," METHOMIKA J. Manaj. Inform. Komputerisasi Akunt., vol. 4, no. 2, pp. 94-97, 2020.

[14] Y. K. Arinda, M. A. Rahman, and D. Alamsyah, "Klasifikasi Jenis Bunga menggunakan SVM dengan Fitur HSV dan HOG," Ijccs, no. x, pp. 1-12, 2018.

[15] U. Proboyekti, "Bahan Ajar Rekayasa Perangkat Lunak Agile Software Development," Indonesia.

[16] K. S. Haryana, "Penerapan Agile Development Methods Dengan Framework Scrum Pada Perancangan Perangkat Lunak Kehadiran Rapat Umum Berbasis Qr-Code," J. Comput. Bisnis, vol. 13, no. 2, pp. 70-79, 2019.

[17] R. Pratama, A. F. Assagaf, and F. Tempola, "Deteksi Kematangan Buah Tomat Berdasarkan Fitur Warna Menggunakan 
JURNAL MEDIA INFORMATIKA BUDIDARMA

Volume 5, Nomor 1, Januari 2021, Page 308-316

ISSN 2614-5278 (media cetak), ISSN 2548-8368 (media online)

Available Online at https://ejurnal.stmik-budidarma.ac.id/index.php/mib DOI 10.30865/mib.v5i1.2562

Metode Transformasi Ruang Warna HIS,” JIKO (Jurnal Inform. dan Komputer), vol. 2, no. 2, pp. 81-86, 2019, doi: http://dx.doi.org/10.33387/jiko.

[18] N. Arifin and I. S. Areni, "Klasifikasi Kematangan Stroberi Berbasis Segmentasi Warna dengan Metode HSV," vol. 23, no. 2, pp. 113-116, 2019, doi: 10.25042/jpe.112019.03.

[19] H. Risman, D. Nugroho, and Y. R. WU, "Penerapan Metode K-Nearest Neighbor Pada Aplikasi," Jural TIKomSiN, vol. 3 , no. 2, pp. 19-25, 2013

[20] N. K. S. Ningrum and T. Ellen, "Ekstraksi Warna Berdasarkan Rgb Untuk Menentukan Tingkat Kematangan Daun Tembakau," Pros. SNATIF Ke -5 Tahun 2018, pp. 96-101, 2019. 